\title{
Combined Sciatic-Lumbar Plexus Block with General Anesthesia: Efficacy in Preventing Tourniquet-Induced Hemodynamic Changes
}

\author{
Raham Hasan Mostafa \\ Faculty of Medicine, Ain Shams University, Cairo, Egypt \\ Email:rahamhasan@yahoo.com
}

How to cite this paper: Mostafa, R.H. (2018) Combined Sciatic-Lumbar Plexus Block with General Anesthesia: Efficacy in Preventing Tourniquet-Induced Hemodynamic Changes. Open Journal of Anesthesiology, 8, 100-111. https://doi.org/10.4236/ojanes.2018.83011

Received: February 13, 2018

Accepted: March 26, 2018

Published: March 29, 2018

Copyright $\odot 2018$ by author and Scientific Research Publishing Inc. This work is licensed under the Creative Commons Attribution International License (CC BY 4.0).

http://creativecommons.org/licenses/by/4.0/ (c) (i) Open Access

\begin{abstract}
Background: Pneumatic arterial tourniquet is a utilized strategy in limb surgeries to provide bloodless field to facilitate surgical procedure. Be that as it may, arterial tourniquet has numerous injurious impacts including hemodynamic changes and tourniquet-induced pain which sometimes can be severe and intolerable. Objectives: Our primary aim was to assess the impact of performing "Lumbar Plexus Block and sciatic nerve block" with General Anesthesia (GA) on the degree of arterial tourniquet-induced hemodynamic effects. On the other hand, our secondary aims were: amount of postoperative analgesic prerequisites, patient satisfactory score and documented side effects. Settings and Design: Ain Shams University, Orthopedic operating theatre; a prospective, randomized, double-blind study. Methods and Material: The physical status of 50 patients (both sexes) including I and II patients from American Society of Anesthesiologists, whose ages are from 20 - 40 years, is not so ideal when they are undergoing elective knee Arthroscopy. The duration lasts no more than ninety minutes under GA with application of tourniquet. Patients were allotted haphazardly to one of two groups. In Group C (Control group): Only GA. In Group B: LPB and sciatic nerve block were performed just before GA administration. Intraoperative hemodynamics was recorded at specific timings. Results: Incidence of tourniquet induced hypertension (TIH) was markedly less with Group B at: forty five, sixty, seventy five mins after tourniquet inflation and just before tourniquet deflation. Also, the total ketorolac consumption during first 24 hours of postoperative period was significantly less with Group B $(\mathrm{p}<0.001)$. Finally, patient satisfaction was significantly higher in Group B. Conclusions: Combined Sciatic-Lumbar plexus blocks when combined with general anesthesia were very effective in attenuating TIH.
\end{abstract}

\section{Keywords}

General Anesthesia, Lumbar Plexus Blocks, Orthopedic Surgery, 
Postoperative Analgesia, Sciatic Nerve Block, Tourniquet Induced Hemodynamic Changes

\section{Introduction}

Knee arthroscopy is standout amongst the most commonly performed orthopedic procedures for the diagnosis \& treatment of knee diseases [1]. Different types of anesthetic techniques including local, regional, \& general anesthesia have been utilized effectively for this surgical procedure [2] [3] [4] [5] [6]. More recently, peripheral nerve block techniques such as combined lumbar plexus block (LPB) \& sciatic nerve block have also been used whether as sole anesthetic technique or as an adjunct to general anesthesia. The combined lumbar plexus-sciatic nerve block technique provides more comfortable intraoperative anesthesia \& preferable postoperative analgesia than the femoral-obturator-sciatic nerve block technique [7]-[12].

Pneumatic tourniquets are generally utilized in limb surgeries to give a bloodless field \& to facilitate surgical dissection. Notwithstanding, it is vital to appreciate their potential complications, e.g., tourniquet pain, TIH, limb ischemia, nerve injury \& reperfusion injury, which may be minimized by understanding the proper technique and precautions of tourniquet use, cautious patient assessment to exclude contraindications \& by using modern pneumatic tourniquets which are intended to limit the rate of this potential entanglement [13].

Many theories state that tourniquet pain is predominantly mediated by unmyelinated, slowly conducting C-fibers which are affected to a less extent by the compression of tourniquet inflation than larger fibers [14].

An ascent in SBP or DBP of more than $30 \%$ in patients with a tourniquet inflated for more than 30 mins has been termed as TIH [15]. TIH occurs more during lower limb surgeries \& under general anesthesia. It could be serious in patients with ischemic heart diseases, glaucoma \& neurological diseases.

It has been suggested that TIH \& tachycardia denote activation of the sympathetic nervous system in response to the development of tourniquet pain [16].

Different medications like ketamine, remifentanil, dextromethorphan, ketorolac, dexmedetomidine \& clonidine have been utilized intravenously to lessen TIH [17] [18] [19] [20] [21].

The aim of this study was to test the effectiveness of combined lumbar plexus block and sciatic nerve block in lessening TIH. Postoperative analgesia, patient satisfaction score \& side effects if any, were studied as secondary objectives.

\section{Subjects and Methods}

The study protocol was affirmed by the local ethical committee of A in Shams University Hospital, and written, informed consent was gotten from all patients. A sum of fifty patients undergoing elective knee arthroscopic surgery with the 
utilization of pneumatic tourniquet under general anesthesia were enlisted in the study amongst January and September 2017. All of the patients were American Society of Anesthesiologists (ASA) physical status I and II and between the ages of twenty and forty years. Exclusion criteria included epilepsy, peripheral neuropathy, refusal to participate in the study, hypersensitivity to drugs utilized for analgesia; infection at the site of puncture and hemorrhagic diathesis. Patients were randomized by a PC produced table of random numbers to receive either: sciatic lumbar plexus block with general anesthesia (Group B = Block group) or GA only (Group C $=$ Control group). All anesthetic blocks were performed by the same anesthesiologist using nerve stimulator technique.

After an 18-gauge intravenous (IV) cannula was inserted into the hand, patients were premedicated with two mg of midazolam forty five minutes before the surgical procedure.

Demographic data were recorded on arrival at the operating-theatre\& routine monitoring like electrocardiogram, pulse oximetry, noninvasive blood pressure \& capnography were established.

For Group B: The patient was placed in the lateral (Sims) position with the side to be blocked uppermost. The hip on the side to be blocked is flexed to $30^{\circ}$ and the ipsilateral knee flexed to $90^{\circ}$. The skin is sterilized with antiseptic solution. Lumbar plexus blocks were performed using the approach portrayed by Winnie et al. [12]. The needle in the lumbar plexus block was inserted with a slight medial inclination at the crossing point of the intercristal line that was drawn in the horizontal plane at the upper margin of the iliac crests and a line drawn parallel to the spine through the posterior superior iliac spine (PSIS). Immediately after performing the lumbar plexus block, the sciatic nerve was blocked utilizing the classical posterior approach as described by Labat [22]. A first line was drawn from the midpoint of the greater trochanter to the PSIS, and a second line was drawn to the sacral hiatus. The puncture was performed at the intersection of a third line, emerging perpendicularly from the first line at its midpoint and the second line. Patients undergoing lumbar plexus block received forty $\mathrm{mL}$ of $0.25 \%$ bupivacaine. Twenty milliliters of the same solution was used for the sciatic nerve block. A nerve stimulator (Stimuplex, Melsungen, Germany) with a $10-\mathrm{cm}, 21$-gauge needle was used to locate the nerve. Stimulation frequency was 2 hertz and pulse width was $0.1 \mathrm{~ms}$. Initial intensity of the stimulating current was $1 \mathrm{~mA}$ and gradually decreased to $0.5 \mathrm{~mA}$. In all cases, $0.5 \%$ chlorhexidine alcohol was used for antisepsis of the skin of both the lumbar \& gluteal regions, and the blocks were performed using aseptic techniques, using fenestrated sterile fields and sterile gloves and face mask.

After completion of the anesthetic injection, hemodynamic variables were recorded. Then patients were placed supine without evaluating the success or extension of the blockade.

GA was induced for all patients in both groups by another anesthetist who is blinded regarding patients' group. After patient oxygenation with $100 \%$ oxygen for 1 minute, $2 \mu \mathrm{g} / \mathrm{kg}$ of fentanyl, $2 \mathrm{mg} / \mathrm{kg}$ of propofol, and $0.5 \mathrm{mg} / \mathrm{kg}$ of atracu- 
rium were administered intravenously then bag mask ventilation with isoflurane $\&$ $100 \%$ oxygen was started for 3 minutes till intubation was done.

After tracheal intubation, general anesthesia was maintained with isoflurane under controlled mechanical ventilation. Volume controlled ventilation was adjusted to keep end-tidal carbon dioxide tension at 33 - $35 \mathrm{mmHg}$. IV paracetamolone gram was started at the time of skin incision in all patients and administered over twenty min. Atracurium was administered in boluses of ten $\mathrm{mg}$ at 30 40 mins.

The pneumatic tourniquet, over cotton layer was applied on the thigh of the operated side after exsanguinations of the limb by crepe bandage. Inflation of the tourniquet was done to a pressure $100 \mathrm{mmHg}$ above patient's baseline systolic blood pressure (SBP).

Blood pressure (BP) both systolic and diastolic, and heart rate (HR) were recorded at specific timings: before induction of anesthesia and at zero, fifteen, thirty, forty five, sixty and seventy five min after tourniquet inflation, just before tourniquet deflation and at fifteen min after tourniquet deflation. Those observations were recorded by the attending anesthesiologists who were unaware of study groups

Additional dose of fentanyl 50 - $100 \mu \mathrm{g}$ was administered for intraoperative analgesia. To ensure patients' safety, authors had planned that if SBP rose to 200 mmHg or higher, fentanyl $100 \mu \mathrm{g}$ IV would be administered and any further step required to manage hypertension would be left to the discretion of the primary anesthesiologist. Such patients would be excluded from the study.

Crystalloids and colloids were used for hydration. After surgery, tourniquet deflation was started gradually and the patients were extubated after reversal of neuromuscular blockade with intravenous $0.05 \mathrm{mg} / \mathrm{kg}$ neostigmine and 0.01 $\mathrm{mg} / \mathrm{kg}$ atropine, and the patients were shifted to post anesthesia care unit (PACU). In PACU, Pain score were noted by utilizing the verbal rating scale (VRS) of 0 - 10, 0 being no pain, 1 - 3 mild, 4 - 6 moderate, and 7 or more as severe pain. Patients with VRS score of 5 or more received IV infusion of Ketorolac $30 \mathrm{mg}$ as rescue analgesic [23].

VRS scores were recorded hourly after the surgery during a time frame of 6 hours, then on the 12 th, 18 th $\& 24$ th hour thereafter. And total postoperative ketolrolac dose was calculated during this period.

Patient satisfaction was evaluated by questioning them to give a score between 1 (dissatisfaction) and 10 (complete satisfaction) by considering the pain that they had experienced after surgery.

\section{Statistical Analysis Used}

A sample size of 20 achieves $90 \%$ power to detect a mean of 30 percent drop in hemodynamic (blood pressure between the 2 groups paired differences of 30.0 with an estimated standard deviation of differences of 30.0 and with a significance level (alpha) of 0.05000 using a two-sided paired t-test (Figure 1). 
Data was collected, coded, tabulated, and then analyzed using SPSS ${ }^{\circledast}$ computer $^{-}$ software version 21 .

Numerical variables were presented as mean and standard deviation while categorical variables were presented as number of cases.

Unpaired Student's $t$-test was used to analyze parametric data while Chi-square test was used for categorical data analysis. Any difference with p-value $<0.05$ was considered statistically significant.

\section{Results}

There were no statistical differences in patient's demographic data and tourniquet time (Table 1).

The two groups were equivalent regarding their baseline SBP, DBP and HR. After tourniquet inflation a significant rise in SBP, DBP and heart rate was found in Group (C) when compared to Group (B) at forty five, sixty, seventy five min after tourniquet inflation and just before tourniquet deflation $(p<0.001)$ (Figures 2-4).

Systolic pressure did not reach $200 \mathrm{mmHg}$ or above in any patient, and therefore none of the recruited patients were barred from the study.

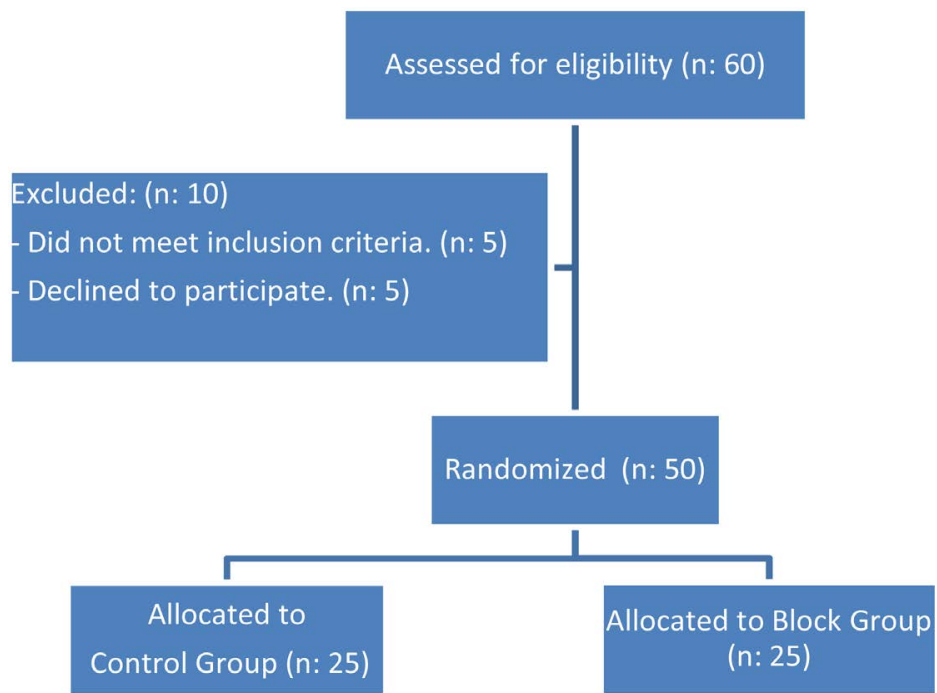

Figure 1. Flow diagram reflecting the RCT trial design.

Table 1. Demographic data.

\begin{tabular}{cccc}
\hline & Group $(\mathrm{C})(\mathrm{n}=25)$ & Group $(\mathrm{B})(\mathrm{n}=25)$ & p-value \\
\hline Age (year) & $31.28 \pm 7.144$ & $31.22 \pm 7.19$ & 0.984 \\
Sex (Male/Female) & $14 / 11$ & $15 / 10$ & 1 \\
BMI $\left(\mathrm{kg} / \mathrm{m}^{2}\right)$ & $23.56 \pm 4.9$ & $24.63 \pm 5.16$ & 0.95 \\
ASA I/II & $6 / 19$ & $5 / 20$ & 1 \\
Tourniquet duration (min) & $80.72 \pm 2.64$ & $82.4 \pm 4.56$ & 0.814 \\
\hline
\end{tabular}

Data are presented as mean \pm SD or as number of patients. $p>0.05$ was considered statistically non-significant. 


\section{SBP}

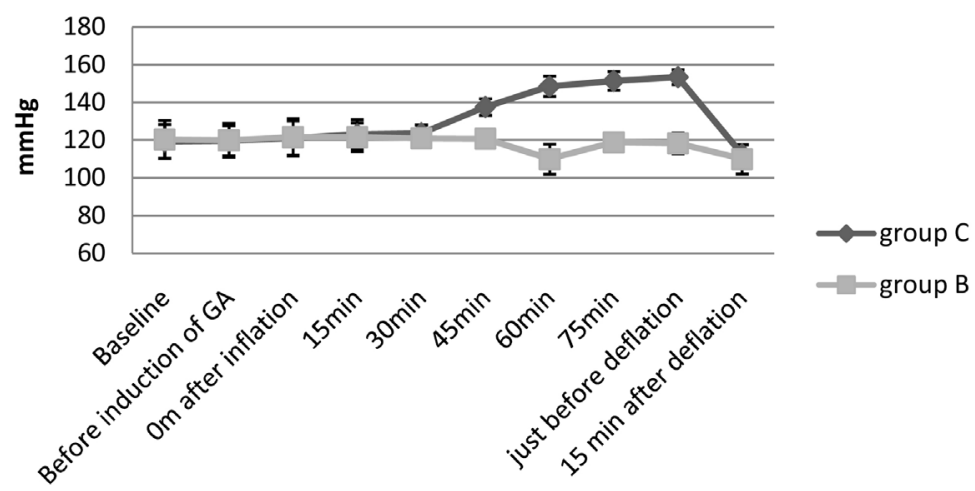

Figure 2. Variation of the systolic arterial blood pressure throughout the operation.

\section{DBP}

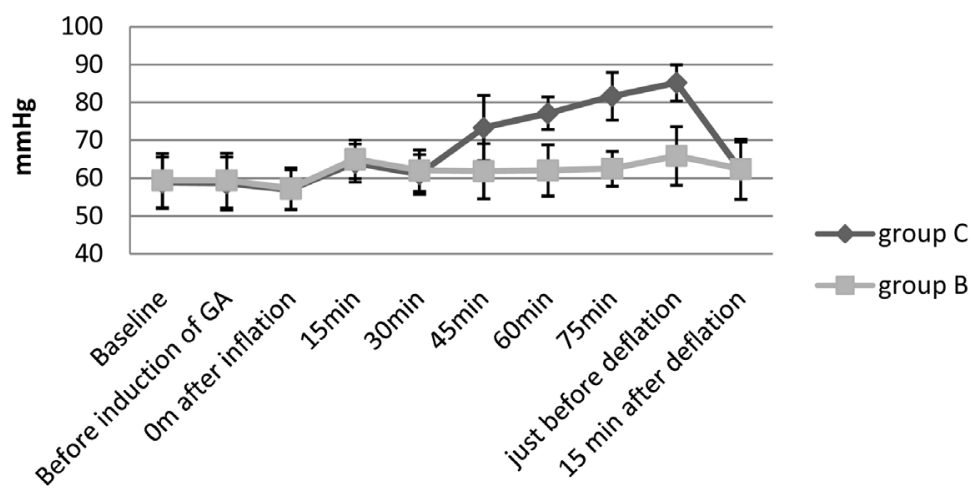

Figure 3. Variation of the diastolic arterial blood pressure throughout the operation.

\section{HR}

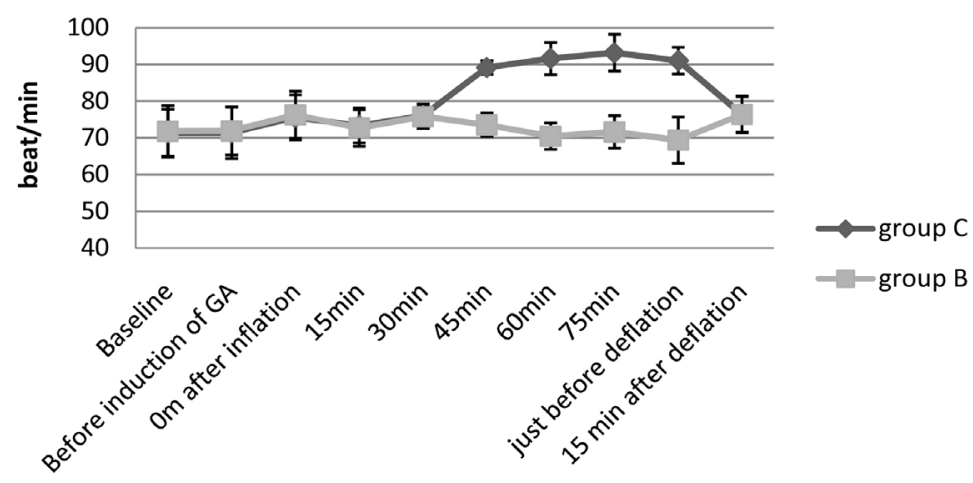

Figure 4. Variation of the Heart rate throughout the operation.

Total postoperative analgesic requirements during first $24 \mathrm{hrs}$ were significantly less in Group (B) when compared to Group (C) ( $<$ 0.001) (Table 2).

Also, the patients' satisfaction scores were higher in Group (B), which were statistically significant $(\mathrm{p}<0.001)$ (Table 3$)$. 
Table 2. Postoperative analgesic requirement consumption.

\begin{tabular}{cccc}
\hline & Group $(\mathrm{C})(\mathrm{n}=25)$ & Group (B) $(\mathrm{n}=25)$ & p-value \\
\hline $\begin{array}{c}\text { Postop analgesic Consumption } \\
\text { during 1st 24 hours } \\
\text { (Ketorolac dose in mg) }\end{array}$ & $80.4 \pm 14.28$ & $14.69 \pm 10.8$ & $<0.001$ \\
\hline
\end{tabular}

Data are presented as mean $\pm \mathrm{SD}$ or median (IQR).

Table 3. Postoperative satisfaction score.

\begin{tabular}{cccc}
\hline & Group (C) $(\mathrm{n}=25)$ & Group $(\mathrm{B})(\mathrm{n}=25)$ & $\mathrm{p}$-value \\
\hline Satisfaction score & $3(2-3)$ & $9(9-10)$ & $<0.001$ \\
\hline
\end{tabular}

Data are presented as mean \pm SD or median (IQR).

\section{Discussion}

Tourniquets are useful aids for limb procedures as they decrease the blood loss during surgery and provide a relatively bloodless field for the surgeon if used properly [24]. HR, SBP, and DBP may increase after $30-60 \mathrm{~min}$ of tourniquet inflation due to ischemia and tourniquet pain. These changes continue until tourniquet deflation and inadequately react to analgesic drugs or increasing the depth of anesthesia [25]. Eutectic mixture of local anesthetic (EMLA) cream application [26] [27], LAs given via the neuraxial route with or without opioids [28]-[33], various intravenous agents as: ketorolac [34], dexmedetomidine [35], Clonidine [36] [37] [38] and ketamine [36] have also been used intravenously to attenuate this pain and subsequent hemodynamic changes.

Here, we suggested that performing combined sciatic lumbar plexus block with GA can abolishes or markedly attenuates tourniquet induced pain and subsequent hemodynamic changes. Although LPB is applied as an anesthetic method in a few studies in combination with sciatic block [39] [40], its usage is commonly limited to perioperative pain management in hip [41] [42] and knee surgeries [43].

We added combined sciatic and lumbar plexus block to GA and evaluated their effect on attenuating TIH in patients undergoing arthroscopic knee surgery under general anesthesia. We additionally compared amount of postoperative analgesic requirements and the degree of satisfaction experienced by patients in both the groups.

We saw that, SBP, DBPand HR fundamentally increased at forty five, sixty, seventy five min after tourniquet inflation and just before tourniquet deflation in the control group as compared to sciatic lumbar plexus group ( $p<0.001)$. In another words, $\%$ of TIH was less with sciatic lumbar plexus group $(\mathrm{p}<0.001)$ at the past meant timings. Likewise, the total ketorolac utilization amid first 24 hours of postoperative period was significantly less in the sciatic lumbar plexus group compared to the control group $(\mathrm{p}<0.001)$. Finally, Patient satisfaction was altogether higher in sciatic lumbar plexus group than control group $(\mathrm{p}<$ $0.001)$. 
This is probably the 1st study discussing the possibility of attenuating TIH effectively using combined sciatic lumbar plexus block under general anesthesia, so finding similar studies was very challenging.

In a study made by Luber and his colleagues, he showed that combined sciatic lumbar plexus block can be used successfully as a sole anesthetic technique for total knee arthroplasty with low \% of tourniquet pain and subsequent hemodynamic changes. Also, they showed that lumbar plexus block appears to have advantages for early postoperative analgesia, leading to increased patient comfort and satisfaction and this goes with our results [44].

Another study by Tharwat was in concordance with our results. Tharwat, in his investigation of 48 patients totally, compared the combination of Posterior lumbar plexus-sciatic (PLPS) nerve block with the combination of Femoral-obturator-sciatic (FOS) nerve block for ACL reconstruction. He found that the two combinations are comparable intraoperative regarding stable hemodynamics and minimal tourniquet pain, but the PLPS nerve block offered better post-operative analgesia with less opioid consumption [45].

In a study done by Horasanli and his colleagues, they demonstrated that combined lumbar plexus and sciatic nerve block provides intraoperative hemodynamic stability and low \% rate of complications. Surprisingly, the (LPSB) showed lesser patient satisfaction (but higher surgeon satisfaction) but with no statistical difference. Likewise, the duration of analgesia in the LPSB group was moderately short in their study when contrasted to other studies (but longer when compared with epidural group). This outcome may be because of the lower concentration and dose of ropivacaine in the LPSB group [46].

Supporting our results in regards of patient satisfaction, Raimer et al. recorded that patient satisfaction with the anesthetic technique was high, and no huge contrasts were observed between psoas compartment-sciatic block analgesia and epidural analgesia for postoperative pain therapy after knee arthroplasty [47].

Contrary to our results, Bareka and his colleagues showed higher VAS scores during tourniquet inflation in PLPS group (when compared with FOS Group) with subsequent more intraoperative fentanyl consumption and this difference was statistically significant [48]. Also, the post-operative pain scores were higher for the PLPS group, and this is additionally reflected in the higher morphine utilization by this group. All patients in both groups were extremely satisfied by their anesthesia-analgesia and the total management. The higher rate of success with the FOS block in comparison with PLPS block can be clarified by the way that in the FOS group the local anesthetic is infused with the use of ultrasound around the femoral and the obturator nerve, while in the PLPS group it is infused blindly into the plexus.

This fact (addition of obturator nerve block) could likewise explain the less VAS score in the FOS group during tourniquet inflation and autograft harvesting since the obturator nerve is responsible for the sensory innervation of the skin of the medial aspect of the thigh and it is also responsible for the motor innervation of the gracilis. Subsequently, the higher rate of conversion to general 
anesthesia in the PLPS group, on account of agony and distress during surgery, can be ascribed to the inferior quality of the obturator nerve block with this technique.

A limitation of our study is that we did not utilize the bispectral index or electroencephalogram to guarantee similar anesthetic depth in all patients because of unavailability of equipment. Also, our research population comprised of patients belonging to American Society of Anesthesiologists physical status I and II, while the risk related to TIH would be possibly more hurtful in patients with pre-existing cardiovascular disease, especially ischemic heart disease. We, hence, suggest that future research ought to incorporate this patient population in order to evaluate the degree of attenuation of TIH in patients who might really profit from this effect.

\section{Conclusion}

We presume that performing combined Sciatic-Lumbar plexus block as an adjunct to GA, is exceptionally powerful in counteracting tourniquet-induced rise in arterial pressure.

\section{Conflict of Interest}

There was no conflict of interest.

\section{Acknowledgements}

Declared none.

\section{References}

[1] Di Benedetto, P., Bertini, L., Casati, A., Borghi, B., Albertin, A. and Fanelli, G. (2001) A New Posterior Approach to the Sciatic Nerve Block: A Prospective, Randomized Comparison with the Classic Posterior Approach. Anesthesia \& Analgesia, 93, 1040-1044. https://doi.org/10.1097/00000539-200110000-00049

[2] Casati, A., Magistris, L., Fanelli, G., Beccaria, P., Cappelleri, G., Aldegheri, G., et al. (2000) Small-Dose Clonidine Prolongs Postoperative Analgesia after Sciatic-Femoral Nerve Block with $0.75 \%$ Ropivacaine for Foot Surgery. Anesthesia \& Analgesia, 91, 388-392.

[3] Cuvillon, P., Ripart, J., Jeannes, P., Mahamat, A., Boisson, C., L'Hermite, J., et al. (2003) Comparison of the Parasacral Approach and the Posterior Approach, with Single- and Double-Injection Techniques, to Block the Sciatic Nerve. Anesthesiology, 98, 1436-1441. https://doi.org/10.1097/00000542-200306000-00021

[4] Hadzic, A. and Vloka, J.D. (1998) A Comparison of the Posterior versus Lateral Approaches to the Block of the Sciatic Nerve in the Popliteal Fossa. Anesthesiology, 88, 1480-1486. https://doi.org/10.1097/00000542-199806000-00010

[5] Hall, M.J. and Lawrence, L. (1998) Ambulatory Surgery in the United States, 1996. Adv Data, 1-16.

[6] Zetlaoui, P.J. and Bouaziz, H. (1998) Lateral Approach to the Sciatic Nerve in the Popliteal Fossa. Anesthesia \& Analgesia, 87, 79-82.

[7] Ganidagli, S., Cengiz, M., Baysal, Z., Baktiroglu, L. and Sarban, S. (2005) The Com- 
parison of Two Lower Extremity Block Techniques Combined with Sciatic Block: 3-in-1 Femoral Block vs. Psoas Compartment Block. International Journal of Clinical Practice, 59, 771-776. https://doi.org/10.1111/j.1368-5031.2005.00414.x

[8] Dilger, J.A. (2000) Lower Extremity Nerve Blocks. Anesthesiology Clinics of North America, 18, 319-340. https://doi.org/10.1016/S0889-8537(05)70166-8

[9] Tokat, O., Turker, Y.G., Uckunkaya, N. and Yilmazlar, A. (2002) A Clinical Comparison of Psoas Compartment and Inguinal Paravascular Blocks Combined with Sciatic Nerve Block. Journal of International Medical Research, 30, 161-167. https://doi.org/10.1177/147323000203000208

[10] Kaloul, I., Guay, J., Cote, C. and Fallaha, M. (2004) The Posterior Lumbar Plexus (Psoas Compartment) Block and the Three-in-One Femoral Nerve Block Provide Similar Postoperative Analgesia after Total Knee Replacement. Canadian Journal of Anesthesia, 51, 45-51. https://doi.org/10.1007/BF03018546

[11] Elmas, C., Elmas, Y., Gautschi, P. and Uehlinger, P. (1992) Combined Sciatic 3-in-1 Block. Application in Lower Limb Orthopedic Surgery. Der Anaesthesist, 41, 639-643.

[12] Winnie, A.P., Ramamurthy, S. and Durrani, Z. (1974) Plexus Blocks for Lower Extremity Surgery. Anesthesiology Review, 1, 11-16.

[13] Oragui, E., Parsons, A., White, T., Longo, U.G. and Khan, W.S. (2011) Tourniquet Use in Upper Limb Surgery. Hand, 6, 165-173.

https://doi.org/10.1007/s11552-010-9312-6

[14] Gielen, M.J. and Stienstra, R. (1991) Tourniquet Hypertension and Its Prevention: A Review. Regional Anesthesia and Pain Medicine, 16, 191-194.

[15] Tetzlaff, J.E., O’Hara Jr., J., Yoon, H.J. and Schubert, A. (1997) Tourniquet Induced Hypertension Correlates with Autonomic Nervous System Changes Detected by power Spectral Heart Rate Analysis. Journal of Clinical Anesthesia, 9, 138-142. https://doi.org/10.1016/S0952-8180(97)00238-9

[16] Arai, Y.C., Ogata, J., Matsumoto, Y., Yonemura, H., Kido, K., Uchida, T., et al. (2004) Preoperative Stellate Ganglion Blockade Prevents Tourniquet-Induced Hypertension during General Anesthesia. Acta Anaesthesiologica Scandinavica, 48, 613-618. https://doi.org/10.1111/j.0001-5172.2004.00389.x

[17] Park, J.W., Jung, Y.H., Baek, C.W., Kang, H. and Cha, S.M. (2007) Effects of Low Dose Ketamine on Tourniquet Induced Haemodynamic Responses during General Anaesthesia. Journal of International Medical Research, 35, 600-608. https://doi.org/10.1177/147323000703500504

[18] Jung, J.Y., Han, J.H., Yi, J.W. and Kang, J.M. (2012) Remifentanil Prevents Tourniquet Induced Arterial Pressure Increase in Elderly Orthopedic Patients under Sevoflurane/ $\mathrm{N}_{2} \mathrm{O}$ General Anesthesia. International Journal of Medical Sciences, 9, 311-315. https://doi.org/10.7150/ijms.4369

[19] Yamashita, S., Yamaguchi, H., Hisajima, Y., Ijima, K., Saito, K., Chiba, A. et al. (2004) Preoperative Oral Dextromethorphan Attenuate Tourniquet Induced Arterial Blood Pressure and Heart Rate Increases in Knee Cruciate Ligament Reconstruction Patients under General Anesthesia. Anesthesia and Analgesia, 98, 994-998. https://doi.org/10.1213/01.ANE.0000104610.99716.37

[20] Sunita, K.S. (2016) A Comparative Study of Ketorolac vs Dexmedetomidine to Attenuate Tourniquet Induced Cardiovascular Response in Lower Limb Surgery. Anaesthesia, Pain \& Intensive Care, 20, 404-410.

[21] Honarmand, A. and Safavi, M.R. (2007) Preoperative Oral Dextromethorphan vs. Clonidine to Prevent Tourniquet-Induced Cardiovascular Responses in Orthopaedic Patients under General Anaesthesia. European Journal of Anaesthesiology, 24, 
511-555. https://doi.org/10.1017/S0265021506002055

[22] Labat, G. (1923) Regional Anesthesia: Its Technique and Clinical Applications. W.B. Saunders, Philadelphia.

[23] Seymour, R.A. (1982) The Use of Pain Scales in Assessing the Efficacy of Analgesics in Post-Operative Dental Pain. European Journal of Clinical Pharmacology, 23, 441-444. https://doi.org/10.1007/BF00605995

[24] Sharma, J.P. and Salhotra, R. (2012) Tourniquets in Orthopedic Surgery. Indian Journal of Orthopaedics, 46, 377-383. https://doi.org/10.4103/0019-5413.98824

[25] Zaman, S.M., Islam, M.M., Chowdhury, K.K., Rickta, D., Ireen, S.T., Choudhury, M.R., et al. (2010) Haemodynamic and End Tidal $\mathrm{CO}_{2}$ Changes State after Inflation and Deflation of Pneumatic Tourniquet on Extremities. Mymensingh Medical Journal, 19, 524-528.

[26] Lowrie, A., Jones, M.J. and Eastley, R.J. (1989) Effect of Eutectic Mixture of Local Anaesthetic Agents (EMLA) on Tourniquet Pain in Volunteers. British Journal of Anaesthesia, 63, 751-753. https://doi.org/10.1093/bja/63.6.751

[27] Ogufere, W.E., Giddins, G.E. and Thom, J.S. (1995) Upper Arm Tourniquet Pain in Local Anesthesia Surgery. Journal of Hand Surgery (European Volume), 20, 413-414. https://doi.org/10.1016/S0266-7681(05)80106-8

[28] Choi, I.H., Koh, H. and Kwak, I.Y. (1996) A Comparison of Tourniquet Pain in Spinal Anaesthesia. Korean Journal of Anesthesiology, 31, 371-375.

https://doi.org/10.4097/kjae.1996.31.3.371

[29] Concepcion, M.A., Lambert, D.H., Welch, K.A. and Covino, B.G. (1988) Tourniquet Pain during Spinal Anesthesia: A Comparison of Plain Solution of Tetracaine and Bupivacaine. Anesthesia and Analgesia, 67, 828-832. https://doi.org/10.1213/00000539-198809000-00005

[30] Lee, Y., Tung, M.C., Who, L.H., Lai, K.B., Wong, K.L., Wu, K.H., et al. (1990) The Effect of Epidural Anesthesia on Tourniquet Pain: A Comparison of 2\% Lidocaine and 0.5\% Bupivacaine. Anaesthesiologica Sinica, 28, 459-464. (In Chinese)

[31] Bonnet, F., Diallo, A., Saada, M., Belon, M., Gilbaud, M. and Baico, O. (1989) Prevention of Tourniquet Pain by Spinal Isobaric Bupivacaine with Clonidine. British Journal of Anaesthesia, 63, 93-96. https://doi.org/10.1093/bja/63.1.93

[32] Cherng, C.H., Wong, C.S., Chang, F.L., Ho, S.J. and Lee, C.H. (2002) Epidural Morphine Delays the Onset of Tourniquet Pain during Epidural Lidocaine Anesthesia. Anesthesia \& Analgesia, 94, 1614-1616.

[33] Okamoto, T., Mitsuse, T., Kashiwagi, T., Iwaane, E., Sakata, Y., Masuda, K., et al. (1996) Prophylactic Epidural Administration of Fentanyl for the Suppression of Tourniquet Pain. Journal of Anesthesia, 10, 5-9. https://doi.org/10.1007/BF02482060

[34] Bose, S., Sunder, R.A., Rewari, V. and Saksena, R. (2008) Study of Magnesium, Ketamine, Ketorolac as Adjuvants to Lidocaine in Intravenous Regional Anaesthesia. Conference: American Society of Anesthesiologists Annual Meeting 2008, Orlando, 19 October 2008.

[35] Viscomi, C.M., Friend, A., Parker, C., Murphy, T. and Yarnell, M. (2009) Ketamine as an Adjuvant in Lidocaine Intravenous Regional Anesthesia: A Randomised, Double-Blind, Systemic Control Trial. Regional Anesthesia and Pain Medicine, 34, 130-133. https://doi.org/10.1097/AAP.0b013e31819bb006

[36] Lurie, S.D., Reuben, S.S., Gibson, C.S., DeLuca, P.A. and Maciolek, H.A. (2000) Effect of Clonidine on Upper Extremity Tourniquet Pain in Healthy Volunteers. Re- 
gional Anesthesia and Pain Medicine, 25, 502-505.

https://doi.org/10.1097/00115550-200009000-00011

[37] Gentili, M., Bernard, J.M. and Bonnet, F. (1999) Adding Clonidine to Lidocaine for Intravenous Regional Anesthesia Prevents Tourniquet Pain. Anesthesia \& Analgesia, 88, 1327-1330. https://doi.org/10.1213/00000539-199906000-00024

[38] Gorgias, N.K., Maidatsi, P.G., Kyriakidis, A.M., Karakoulas, K.A., Alvanos, D.N. and Giala, M.M. (2001) Clonidine versus Ketamine to Prevent Tourniquet Pain during Intravenous Regional Anaesthesia with Lidocaine. Regional Anesthesia and Pain Medicine, 26, 512-517. https://doi.org/10.1097/00115550-200111000-00005

[39] Ho, A.M. and Karmakar, M.K. (2002) Combined Paravertebral Lumbar Plexus and Parasacral Sciatic Nerve Block for Reduction of Hip Fracture in a Patient with Severe Aortic Stenosis. Canadian Journal of Anesthesia, 49, 946-950. https://doi.org/10.1007/BF03016880

[40] Asao, Y., Higuchi, T., Tsubaki, N. and Shimoda, Y. (2005) Combined Paravertebral Lumbar Plexus and Parasacral Sciatic Nerve Block for Reduction of Hip Fracture in Four Patients with Severe Heart Failure. Masui. The Japanese Journal of Anesthesiology, 54, 648-652.

[41] Chelly, J.E., Casati, A., Al-Samsam, T., Coupe, K., Criswell, A. and Tucker, J. (2003) Continuous Lumbar Plexus Block for Acute Postoperative Pain Management after Open Reduction and Internal Fixation of Acetabular Fractures. Journal of Orthopaedic Trauma, 17, 362-367. https://doi.org/10.1097/00005131-200305000-00007

[42] Capdevila, X., Macaire, P., Dadure, C., Choquet, O., Biboulet, P., Ryckwaert, Y., et al. (2002) Continuous Psoas Compartment Block for Postoperative Analgesia after Total Hip Arthroplasty: New Landmarks, Technical Guidelines, and Clinical Evaluation. Anesthesia and Analgesia, 94, 1606-1613. https://doi.org/10.1213/00000539-200206000-00045

[43] Hadzic, A., Karaca, P.E., Hobeika, P., Unis, G., Dermksian, J., Yufa, M., et al. (2005) Peripheral Nerve Blocks Result in Superior Recovery Profile Compared with General Anesthesia in Outpatient Knee Arthroscopy. Anesthesia and Analgesia, 100, 976-981. https://doi.org/10.1213/01.ANE.0000150944.95158.B9

[44] Luber, M.J., Greengrass, R. and Vail, T.P. (2001) Patient Satisfaction and Effectiveness of Lumbar Plexus and Sciatic Nerve Block for Total Knee Arthroplasty. The Journal of Arthroplasty, 16, 17-21. https://doi.org/10.1054/arth.2001.16488

[45] Tharwat, A.I. (2011) Combined Posterior Lumbar Plexus-Sciatic Nerve Block versus Combined Femoral-Obturator-Sciatic Nerve Block for ACL Reconstruction. Local and Regional Anesthesia, 4, 1-6. https://doi.org/10.2147/LRA.S15635

[46] Horasanli, E., Gamli, M., Pala, Y., Erol, M., Sahin, F. and Dikmen, B. (2010) A Comparison of Epidural Anesthesia and Lumbar Plexus-Sciatic Nerve Blocks for Knee Surgery. Clinics (Sao Paulo), 65, 29-34. https://doi.org/10.1590/S1807-59322010000100006

[47] Raimer, C., Priem, K., Wiese, A.A., Birnbaum, J., Dirkmorfeld, L.M., Mossner, A., et al. (2007) Continuous Psoas and Sciatic Block after Knee Arthroplasty: Good Effects Compared to Epidural Analgesia or I.V. Opioid Analgesia: A Prospective Study of 63 Patients. Acta Orthopaedica, 78, 193-200. https://doi.org/10.1080/17453670710013672

[48] Bareka, M., Hantes, M., Arnaoutoglou, E. and Vretzakis, G. (2018) Superior Perioperative Analgesia with Combined Femoral-Obturator-Sciatic Nerve Block in Comparison with Posterior Lumbar Plexus and Sciatic Nerve Block for ACL Reconstructive Surgery. Knee Surgery, Sports Traumatology, Arthroscopy, 26, 478-484. 